\title{
MANAJEMEN TANAMAN SEHAT BUDIDAYA PADI UNTUK MENINGKATKAN PRODUKSI DAN PENDAPATAN USAHATANI PADI
}

\author{
Harfafina Riastyadiningrum ${ }^{1)^{*}}$, Ida Ekawati ${ }^{2)}$ \\ 1)* Mahasiswa Program Studi Agribisnis Fakultas Pertanian Universitas Wiraraja \\ Madura \\ 2) Dosen Fakultas Pertanian, Universitas Wiraraja Madura \\ e-mail : idaekawatee@yahoo.co.id ${ }^{2)}$
}

\begin{abstract}
ABSTRAK
Pengelolaan usahatani padi dengan penggunaan pupuk dan pestisida anorganik berdampak pada keseimbangan agroekosistem, dan mengancam keberlanjutan produksi. Tujuan penelitian menganalisis pengaruh penerapan MTS terhadap produksi dan pendapatan usahatani padi serta mengetahui faktor produksi yang dominan.Pengumpulan data menggunakan metode survey. Data dianalisis dengan uji t dan fungsi produksi Cobb Douglas. Hasil analisis menunjukkan penerapan MTS signifikan meningkatkan produksi dan pendapatan usahatani padi. Luas lahan merupakan faktor dominan yang mempengaruhi produksi padi. MTS perlu diterapkan berkelanjutan agar keberlanjutan produksi tercapai.
\end{abstract}

Kata Kunci: Manajemen Tanaman Sehat, Pendapatan Petani, Produksi padi, Refugia 


\section{PENDAHULUAN}

Tanaman padi (Oryza sativa L.) termasuk tanaman pangan yang sangat penting dan menjadi makanan pokok lebih dari setengah penduduk dunia karena mengandung nutrisi yang diperlukan tubuh (Pratiwi, 2016).Meningkatnya kebutuhan pangan terutama pada komoditas padi mendorong insan pertanian untuk meningkatkan produktivitas tanaman dan mengembangkan keanekaragaman bahan pangan. Berbagai cara telah dilakukan untuk meningkatkan produksi dan tanpa disadari bahwa penggunaan pupuk anorganik dan pestisida anorganik yang kurang tepat akan berdampak pada perubahan keseimbangan, sehingga memberikan efek negatif terhadap lingkungan dan manusia (Hariono, 2017). Oleh karena itu, diperlukan suatu teknologi ramah lingkungan yang dikembangkan untuk mengendalikan OPT yang didasarkan kepada konsep pengendalian hama dan penyakit dengan mempertimbangkan ekosistem (Effendi, 2009).

Manajemen Tanaman Sehat (MTS) merupakan salah satu strategi bagi petani untuk menerapkan pengendalian hama terpadu (PHT) dimana dalam penerapannya mulai dari proses pengolahan lahan, peningkatan makro organik, pemanfaatan jerami, kegiatan penanaman, penggunaan pupuk organik dan pemanfaatan tanaman pinggir yaitu tanaman refugia (Tabloid Sinar Tani, 2018).

Demikian halnya dengan Kabupaten Sumenep, beberapa kecamatan telah dilaksanakan program Manajemen Tanaman Sehat (MTS), yang salah satunya telah dilakukan oleh beberapa petani di Desa Saronggi. Namun perlu dilakukan kajian mengenai penerapan MTS pada

usahatani padi, apakah dengan menerapkan program MTS pada usahatani padi akan meningkatkan produktivitas dan pendapatan sehingga akan mendorong petani untuk menerapkan program ini pada usahatani padi.

Tujuan penelitian ini adalah menganalisis pengaruh penerapan MTS terhadap produksi dan pendapatan usahatani padi dan faktor produksi yang dominan menentukan produksi padi dengan sistem pengelolaan MTS.

\section{METODE PENELITIAN}

Penelitian dilaksanakan di Desa Saronggi Kecamatan Saronggi Kabupaten Sumenep dengan pertimbangan bahwa Desa Saronggi Kecamatan Saronggi Kabupaten Sumenep merupakan salah satu desa yang menerapkan manajemen tanaman sehat (MTS) pada tanaman padi.

Data yang dikumpulkan dalam penelitian ini bersumber dari data primer dan data sekunder. Data primer diperoleh dari hasil wawancara dengan menggunakan alat bantu berupa kuisioner yang pertanyaannya disampaikan langsung kepada petani padi (responden), serta melakukan observasi dan dokumentasi. Data sekunder diperoleh dari literaturliteratur yang berhubungan dengan penelitian, buku, kantor desa atau instansi terkait dalam hal ini yaitu Dinas Pertanian Kabupaten Sumenep dan jurnal.

Teknik pengambilan sampel
menggunakan metode r acak
proporsional. Jumlah sampel
ditentukan dengan menggunakan
rumus slovin, sehingga diperoleh 55
petani sampel. Teknik analisis yang
digunakan yaitu:


a) Uji Beda Rata-Rata dua sampel saling bebas.

$\mathrm{t}=\frac{x_{1}-R_{2}}{\sqrt{\frac{\left(n_{1}-1\right) S_{1}^{2}+\left(n_{2}-1\right) S_{2}^{2}}{n_{1}+n_{2}-2}\left(\frac{1}{n_{1}}+\frac{1}{n_{2}}\right)}}$

Dimana $\mathrm{t}$ adalah Produksi atau Pendapatan, $\bar{X}_{1} \quad$ adalah Rata-rata

produksi/pendapatan usahatani yang menerapkan MTS, $\bar{X}_{2}$ adalah Ratarata produksi/pendapatan usahatani yang tidak menerapkan MTS, S $_{1}$ adalah Standart Deviasi usahatani padi yang menerapkan MTS, $S_{2}$ adalah Standart Deviasi usahatani padi yang tidak menerapkan MTS, n ${ }_{1}$ adalah Jumlah sampel usahatani padi yang menerapkan MTS, nzadalah Jumlah sampel usahatani padi yang tidak menerapkan MTS.

b) Model fungsi produksi Cobb Douglas.

Untuk mengetahui faktor produksi manakah yang dominan menentukan produksi padi dengan sistem pengelolaan MTS digunakan metode model fungsi produksi Cobb Douglas.

$Y=a X 1^{b 1} X 2^{b 2} X 3^{b 3} X 4^{b 4} X 5^{b 5}$

Dimana $Y$ adalah Produksi, a adalah konstanta, $\mathrm{b}^{1-5}$ adalah koefisien regresi, X1 adalah Luas Lahan, X2 adalah Tenaga Kerja, X3 adalah Bibit, X4 adalah Pupuk, X5 adalah Pestisida.

\section{HASIL DAN PEMBAHASAN}

Penerapan Manajemen Tanaman Sehat (MTS) Di Tingkat Petani

Penerapan

Manajemen

Tanaman Sehat (MTS) di Desa Saronggi merupakan strategi bagi petani untuk menerapkan pengendalian hama terpadu (PHT). Penerapan MTS oleh petani sesuai dengan rekomendasi teknis MTS yaitu petani menggunakan tanaman refugia untuk meningkatkan keanekaragaman hayati di sawah, jenis refugia yang digunakan dalam pengelolaan MTS adalah kenikir. Menurut Qomariyah (2017) keanekaragaman serangga tertinggi adalah kombinasi kenikir dengan padi organik, karena didukung oleh tanaman berbunga dengan warna cerah, terdapat nektar serta lokasinya berdampingan dengan tanaman padi organik dalam fase generatif. Kehadiran tanaman berbunga dapat meningkatkan keragaman dan kelimpahan antropoda pada tanaman padi termasuk musuh alami sehingga dapat menekan serangan hama (Kurniawati, 2015). Tanaman kenikir mengandung saponin, flavonoida, polifenol dan minyak atsiri. Daunnya dapat digunakan sebagai pengusir serangga (Fikri dan Elly, 2012).

Petani juga melakukan pembenaman jerami sisa panen sebelumnya untuk menambah bahan organik bagi tanah. Untuk pembenihan petani menggunakan benih bersertifikat dan seleksi benih dengan merendam dalam larutan air garam, kemudian benih yang terpilih di rendam dalam larutan PGPR selama 24 jam.Menurut Taufik (2010) aplikasi PGPR pada benih mampu meningkatkan pertumbuhan perkecambahan dibandingkan dengan benih tanpa perlakuan PGPR.

Pengelolaan MTS di Desa Saronggi menggunakan pupuk organik sesuai dengan SOP (Standar Operasional Prosedur) dengan dosis yang digunakan 1-2 Ton/Ha, penggunaan agen hayati PGPR, pengendalian hama secara terpadu dan pemupukan anorganik secara efisien. 
Pupuk organik berguna untuk memperkaya hara, bahan organik tanah, dan memperbaiki sifat fisik, kimia dan biologi tanah, terutama kandungan unsur organik (Bouajila dan Sanaa, 2011).Bahan Organik juga dapat berperan sebagai sumber energy dan makanan mikroba PGPR sehingga bermanfaat untuk meningkatkan aktivitas mikroba dalam penyediaan hara bagi tanaman (Shofiah dan Tyasmoro, 2018).Pupuk cair PGPR yang digunakan petani diperoleh dari membeli di Laboratorium Pengamatan Hama dan Penyakit Tanaman Pangan dan Hortikultura Kabupaten Pamekasan. Dosis PGPR yang digunakan petani rata rata 24 liter per hektar. Penggunaan agen hayati PGPR dilakukan pada umur 2, 4 dan 6 minggu setelah tanam. Penggunaan PGPR dengan cara mencampurkan $\pm 100 \mathrm{cc}$ PGPR dengan 1 liter air.

Pengendalian OPT secara terpadu dengan MTS yaitu dengan dilakukan sesuai dengan Prinsip PHT. Jika populasi rendah, aplikasi menggunakan APH (Agen Pengendali Hayati) atau pestisida nabati. Jika populasi sudah diatas ambang pengendalian, menggunakan insektisida kimia. APH adalah organisme yang memusuhi hama. Adapun tujuan PHT adalah meningkatkan pendapatan produksi petani, mempertahankan populasi hama pada taraf yang tidak merugikan tanaman, serta mempertahankan stabilitas ekosistem pertanian (Manueke dkk, 2017) Fungsi tanaman refugia yang di tanam di pinggir sawah yaitu untuk menarik serangga parasitoid dan predator untuk datang memakan nektar, selain itu juga dapat menjadi tempat berlindung bagi serangga musuh alami. Refugia tersebut dapat digunakan sebagai pengendalian hama secara alami dengan memanfaatkan musuh alami yang singgah pada refugia tersebut (Erdiyansyah dkk, 2018)

Penanaman bibit padi menggunakan jarak tanam jajar legowo dengan umur bibit antara 15-17 hari atau bibit muda dengan pengairan dilakukan sesuai kebutuhan tanaman dan berselang.

Pengamatan agroekosistem dilakukan secara rutin untuk mengetahui hal yang mendasari petani dalam pengambilan keputusan tentang pegelolaan lahan. Kegiatan pengamatan agroekosistem meliputi pengamatan perkembangan tanaman, pengamatan OPT yang ada di areal pertanaman, keberadaan musuh alami, kondisi air dan kondisi cuaca.

Produksi Usahatani dengan MTS dan Non MTS

Berdasarkan hasil penelitian rata-rata jumlah produksi yang dihasilkan satu periode tanam sebagai berikut:

Tabel 1

Rata-rata Produksi MTS dan Non MTS

\begin{tabular}{ccc}
\hline No & Jenis Pengelolaan & Produksi \\
\hline 1 & MTS & $6.456^{\mathrm{a}}$ \\
2 & Non MTS & $5.386^{\mathrm{b}}$ \\
\hline
\end{tabular}

Sumber : Data Primer Diolah 2019

Keterangan : Angka yang didampingi oleh huruf yang berbeda menunjukkan berbeda nyata pada taraf kesalahan $\alpha=0,05$ 
Hasil analisis statistik menunjukkan bahwa produksi padi yang menerapkan MTS nyata lebih tinggi dibandingkan dengan produksi padi non MTS. Untuk mengetahui varian produksi padi MTS dan Non MTS dilakukan uji Lavene yang hasilnya menunjukkan tidak ada perbedaan varian antara kedua kelompok (MTS \& Non MTS), karena p-value sebesar 0,237 yang lebih besar dari $\alpha=0,05$. Hal ini perlu dilakukan untuk menentukan rumus uji $\mathrm{t}$ yang dipakai. Oleh karena varian tidak ada perbedaan (homogen) dan jumlah sampel $\left(\mathrm{n}_{1}, \mathrm{n}_{2}\right)$ tidak sama maka digunakan uji $t$ independent dengan varian sama. Hasil uji t menunjukkan bahwa terdapat perbedaan sangat nyata antara produksi padi dengan MTS dan Non MTS. Dalam penerapan MTS petani memanfaatkan tanaman refugia sebagai tempat berlindung musuh alami. Keberagaman fauna karena adanya tanaman refugia akan menyebabkan terbentuknya ekosistem yang lebih stabil, yang akan menjaga keseimbangan komponen ekosistem. Keadaan tanaman berbunga sangat penting untuk melestarikan musuh alami di suatu ekosistem seperti agroekosistem (Kurniawati dan Edhi, 2015). Kehadiran tanaman berbunga dapat meningkatkan keragaman dan kelimpahan antropoda pada tanaman padi termasuk musuh alami sehingga dapat menekan serangan hama (Kurniawati, 2015).

\section{Pendapatan dan Efisiensi Usahatani} dengan MTS dan Non MTS

Pendapatan merupakan selisih antara penerimaan dan biaya total. Besar kecilnya penerimaan selain dipengaruhi oleh cara budidaya yang diterapkan dalam lahan pertaniannya oleh pelaku usahatani. Berikut disajikan tabel penerimaan, pendapatan dan efisiensi usahatani dengan pengelolaan MTS dan Non MTS.

Tabel 2

Rata-rata Penerimaan, Pendapatan dan Efisiensi MTS dan Non MTS Padi per hektar

\begin{tabular}{cccccc}
\hline No & $\begin{array}{c}\text { Jenis } \\
\text { Pengelolaan }\end{array}$ & $\begin{array}{c}\text { Penerimaan } \\
(\mathrm{Rp})\end{array}$ & $\begin{array}{c}\text { Biaya Total } \\
(\mathrm{Rp})\end{array}$ & $\begin{array}{c}\text { Pendapatan } \\
(\mathrm{Rp})\end{array}$ & Efisiensi \\
\hline 1 & MTS & 24.531 .986 & 13.294 .753 & $11.237 .233^{\mathrm{a}}$ & 1,85 \\
2 & Non MTS & 20.466 .800 & 12.861 .127 & $7.605 .673^{\mathrm{b}}$ & 1,59 \\
\hline
\end{tabular}

Sumber : Data Primer Diolah 2019

Keterangan : Angka yang didampingi oleh huruf yang berbeda menunjukkan berbeda nyata pada taraf kesalahan $\alpha=0,05$

Hasil analisis statistik menunjukkan bahwa pendapatan petani yang menerapkan MTS nyata lebih tinggi dibandingkan dengan pendapatan petani Non MTS, meskipun biaya yang dikeluarkan petani MTS lebih tinggi dibandingkan Non MTS tetapi hasil produksi yang diperoleh usahatani dengan MTS lebih tinggi sehingga berpengaruh kepada besarnya penerimaan serta meningkatnya pendapatan.

Rata rata efisiensi per hektar usahatani padi dengan sistem pengelolaan MTS lebih tinggi daripada usahatani dengan Non MTS. Usahatani 
dengan sistem pengelolaan MTS memperoleh R/C Ratio sebesar 1,85 sedangkan pada usahatani Non MTS memperoleh R/C Ratio sebesar 1,59.

Usahatani dengan Pengelolaan MTS dan Non MTS memiliki nilai R/C Ratio lebih dari satu (>1), artinya usahatani dengen pengelolaan MTS dan Non MTS sama-sama efisien. Oleh karena itu usahatani dengan pengelolaan MTS dan Non MTS dapat dikatakan bahwa usahatani yang dilakukan layak diusahakan. Namun tingkat efisiensi pada usahatani dengan pengelolaan MTS lebih tinggi dari usahatani Non MTS.

\section{Fungsi Produksi Cobb Douglas}

Hasil analisis regresi (Overall test) dengan metode Ordinary Least Square (OLS) menunjukkan bahwa pada taraf kesalahan $5 \%$ faktor produksi dalam model berpengaruh nyata terhadap produksi padi.

Nilai $R^{2}$ sangat tinggi yaitu 0,942, hal ini menunjukkan bahwa 94,2\% variasi produksi usahatani padi dipengaruhi oleh variasi luas lahan, tenaga kerja, bibit, pupuk dan pestisida dan hanya $5,8 \%$ yang dipengaruhi oleh faktor lain yang tidak termasuk dalam model.

\section{Tabel 3}

Koefisien Regresi Faktor Produksi Padi

\begin{tabular}{lcc}
\hline \multicolumn{1}{c}{ Variabel } & Koefisien Regresi & Nilai \\
\hline Intercept/konstanta & $\mathrm{b}_{0}$ & 7.280 \\
Luas Lahan (X1) & $\mathrm{b}_{1}$ & 0.783 \\
Tenaga kerja (x2) & $\mathrm{b}_{2}$ & 0.153 \\
Bibit (X3) & $\mathrm{b}_{3}$ & 0.096 \\
Pupuk (X4) & $\mathrm{b}_{4}$ & 0.063 \\
Pestisida (X5) & $\mathrm{b}_{5}$ & -0.083 \\
$\mathrm{R}^{2}$ & 0.942 & \\
\hline
\end{tabular}

Sumber : Data Primer Diolah 2019

Dari data koefisien regresi faktor faktor produksi maka diperoleh persamaan fungsi produksi sebagai berikut:

$\mathrm{Y}=7,280 \cdot \mathrm{X} 1^{0,783} \cdot \mathrm{X} 2^{0,153} \cdot \mathrm{X} 3^{0,096} \cdot \mathrm{X} 4^{0,0}$ ${ }^{63} . \mathrm{X} 5^{-0,083}$

Dimana X1 adalah Luas Lahan, X2 adalah Tenaga Kerja, X3 adalah Bibit, X4 adalah Pupuk, X5 adalah Pestisida.

Model tersebut merupakan model yang baik karena hasil uji $\mathrm{F}$ nyata dan nilai $\mathrm{R}^{2}$ cukup tinggi $(0,942)$. Oleh karena itu model fungsi tersebut dapat digunakan untuk memprediksi produksi padi dengan faktor-faktor produksi yang telah disebutkan sebelumnya.

Hasil analisis faktor produksi secara parsial yang meliputi luas lahan (X1), Tenaga Kerja (X2), Bibit (X3), Pestisida (X5) bepengaruh nyata pada taraf kepercayaan $95 \%$ 
Tabel 4

Tingkat Signifikansi Pengaruh Faktor Faktor Produksi Secara Parsial

\begin{tabular}{|c|c|c|c|}
\hline Variabel & $\mathrm{t}_{\text {hitung }}$ & Sig & Keterangan \\
\hline Konstan & 20.119 & .000 & Berpengaruh nyata \\
\hline Luas lahan & 21.878 & .000 & Berpengaruh nyata \\
\hline Tenaga kerja & 3.653 & .006 & Berpengaruh nyata \\
\hline Bibit & 2.420 & .042 & Berpengaruh nyata \\
\hline Pupuk & 1.122 & .295 & Tidak Berpengaruh nyata \\
\hline Pestisida & -3474 & .008 & Berpengaruh nyata \\
\hline
\end{tabular}

Sumber : : Data Primer Diolah 2019

Luas lahan (X1) berpengaruh nyata dengan nilai koefisien 0,783 yang berarti bahwa setiap adanya penambahan sebesar satu satuan luas lahan akan menaikkan produksi sebesar $0,783 \mathrm{~kg} / \mathrm{ha}$ dengan asumsi variabel lain tetap. Sesuai dengan teori penggunaan lahan pertanian secara ekonomi yang menyebutkan bahwaluas lahan merupakan bagian penting dalam produksi pertanian dan merupakan bagian dari pertanian yang berhubungan erat dengan hasil produksi (Erviyana, 2014).Pengaruh nyata dari faktor produksi luas lahan usahatani padi di Desa Saronggi dengan penambahan luas lahan akan meningkatkan produksi, ini berarti petani masih mampu mengelola usahatani dengan baik.

Tenaga Kerja (X2) berpengaruh nyata dengan nilai koefisien regresi 0,153 yang berarti bahwa setiap penambahan sebesar satu satuan tenaga kerja akan berpengaruh meningkatkan produksi sebesar $0,153 \mathrm{~kg} / \mathrm{ha}$ dengan asumsi variabel lain tetap. Terlihat pada kontribusi penggunaan tenaga kerja relative besar dan berhubungan secara positif terhadap produksi. Tenaga kerja merupakan faktor penting dan perlu diperhitungkan dalam proses produksi komoditas pertanian, karena dengan adanya tenaga kerja yang berkompeten maka proses produksi akan berjalan lancar sehingga dapat berpengaruh pada peningkatan produksi (Gunawan, 2018).

Bibit (X3) berpengaruh nyata dengan koefisien regresi 0,096 yang berarti bahwa setiap penambahan sebesar satu satuan bibit akan berpengaruh meningkatkan produksi sebesar 0,096 $\mathrm{kg} / \mathrm{ha}$ dengan asumsi variabel lain tetap. Bibit merupakan salah satu faktor produksi paling utama dalam usaha meningkatkan produksi padi, penggunaan bibit yang bermutu dapat memberikan peningkatan produksi tanaman pertanian (Juanda, 2016).

Pupuk (X4) tidak berpengaruh nyata terhadap produksi dengan nilai koefisien regresi 0,063 . Hasil analisis mengindikasikan penambahan variabel pupuk dianggap tidak mampu meningkatkan produksi padi. Pemakaian pupuk harus sesuai dosis dan waktu yang tepat, jika diberikan berlebihan pupuk akan berdampak buruk bagi tanaman (Habib, 2013). Pemberian pupuk yang sesuai kebutuhan tanaman dapat mendorong peningkatan produksi pertanian (Rosadi, 2015)

Pestisida (X5) berpengaruh nyata terhadap produksi dengan nilai koefisien regresi $-0,083$ yang berarti setiap penambahan sebesar satu satuan pestisida 
akan berpengaruh menurunkan produksi sebesar 0,083 $\mathrm{kg} / \mathrm{ha}$ dengan asumsi variabel lain tetap. Penggunaan pestisida yang tepat sasaran dan tidak berlebihan akan menurunkan OPT yang menyerang, sedangkan penggunaan pestisida yang berlebihan akan berpengaruh buruk terhadap lingkungan yang akan berdampak pada produksi. Penggunaan pestisida dapat efisien jika pemberiannya tepat sasaran, jenis, waktu, cara dan tepat dosis (Susilowati et al, 2011). Pestisida tidak meningkatkan produksi tetapi menyelamatkan produksi dari serangan hama dan penyakit. Kaitannya dengan peningkatan produksi yaitu karena tanaman yang sehat akan lebih responsif terhadap penyerapan unsur hara sehingga dapat meningkatkan produksi (Fadwiwati dan Tahir, 2013)

\section{KESIMPULAN}

Penelitian ini dapat disimpulkan bahwa produksi dan pendapatan usahatani padi dengan MTS lebih tinggi dibandingkan dengan usahatani padi non MTS. Faktor luas lahan berpengaruh dominan terhadap produksi usahatani padi dengan pengelolaan MTS. Penerapan MTS dapat digunakan sebagai strategi untuk peningkatan produksi padi secara berkelanjutan.

\section{DAFTAR PUSTAKA}

Bouajilia, K. Dan M. Sanaa. 2011. Effects of Organic Amendments on Soil Physico-Chemical and Biological Properties. Journal Mater Journal Of Materials and Environmental Science, Vol.2, No.1: 485-490.

Effendi S.B. 2009. Strategi Pengendalian Hama Terpadu Tanaman Padi Dalam Perspektif Praktek Pertanian Yang Baik (Good
Agricultural

Practices).

Pengembangan Inovasi

Pertanian.Vol. 2, No. 1: 65-78.

Erdiyansyah I, Ningrum D $\mathrm{R} \mathrm{K}$, dan Damanhuri. 2018. Pemanfaatan Tanaman Bunga Marigold dan Kacang Hias Terhadap Anthropoda Pada tanaman Padi Sawah. Jurnal Agriprima. Vol. 2, No. 2: 117-125.

Erviyana, Poppy. 2014. Faktor-Faktor Yang Mempengaruhi Produksi Tanaman Pangan Jagung Di Indonesia. JEJAK Journal of economics and Policy. Vol. 7, No. 2: $194-202$

Fadwiwati, A.Y dan Tahir, A.G. 2013.Analisis Faktor-Faktor Yang Mempengaruhi Produksi dan Pendapatan Usahatani Jagung Di Provinsi Gorontalo.Jurnal Pengkajian dan Pengembangan Teknologi Pertanian. Vol. 16, No. 2: 92-101

Fikri E.N., dan Elly, L., 2013. Efek Jarak Tanam Tomat dengan Kenikir terhadap Serangan Meloidogyne sp pada Tanaman Tomat. Universitas Lambung Mangkurat. Banjarbaru.Agroscientiae. Vol. 20, No.2: 66-68

Gunawan, Felis. 2018. Pengaruh Penggunaan Faktor Produksi Terhadap Produksi Padi di Desa Barogae Kabupaten Bone. Jurnal Pertanian. Universitas Negeri Makassar.

Habib, Akbar. 2013. Analisis FaktorFaktor Yang Mempengaruhi Produksi Jagung. Jurnal Agrium. Vol. 18, No. 1: 79-87 
Hariono, S. 2017. Faktor-Faktor Yang Mempengaruhi Produksi Padi Sawah Organik dan Non Organik Di Kecamatan Muara Bulian Kabupaten Batanghari. Skripsi. Fakultas Pertanian. Universitas Jambi.

Juanda B.R. 2016. Peningkatan Produksi Padi Melalui Potensi Dan Pengembangan Wilayah Produksi Benih Unggul Di Provinsi Aceh. Jurnal Penelitian AGROSAMUDRA. Vol.3 No.2:72-80

Kurniawati, Nia. 2015. Keragaman dan Kelimpahan Musuh Alami Hama Pada Habitat Padi yang Dimanipulasi Tanaman Berbunga. Jurnal Ilmu Pertanian. Vol.18, No.1: 31-36.

Kurniawati, N dan Edhi, M. 2015. Peran tumbuhan berbunga sebagai media konservasi antropoda Musuh alami. Jurnal Perlindungan Tanaman Indonesia. Vol 19, No. 2: 53-59.

Manueke, Jusuf., Assa, Berty H., Pelealu, Aldegongia E. 2017. Rekomendasii Teknologi Pengendalian Hama Secara Terpadu (PHT) Hama Tanaman Padi Sawah (Oryza sativa) Di Desa Makalonsow Kecamatan Tondano Timur Kabupaten Minahasa.Jurnal LPPM Bidang Sains dan Teknologi. Vol.4, No.1: 23-34.

Pratiwi, Sri Hariningsih. 2016. Pertumbuhan dan Hasil Padi (Oryza sativa L.) Sawah Pada Berbagai Metode Tanam Dengan
Pemberian Pupuk Organik. Gontor AGROTECH Science Journal. Vol. 2. No. 2: 1-19.

Qomariyah, Lailatul. 2017. Efek Tanaman Kenikir (Cosmos Sulphureus) sebagai Refugia terhadap Keanekaragaman Serangga Aerial di Sawah Padi Organik Desa Sumberngepoh Kecamatan Lawang Kabupaten Malang. Skripsi. Universitas Islam Negeri (UIN) Maulana Malik Ibrahim Malang.

Rosadi, A. H. Y. 2015. Kebijakan Pemupukan Berimbang untuk Meningkatkan Ketersediaan Pangan Nasional. Jurnal Pangan. Vol.24, No.1: 1-14.

Shofiyah, D K R dan Tyasmoro, S Y. 2018.Aplikasi PGPR (Plant Growth Promoting Rhizobabacteria) Dan Pupuk Kotoran Kambing Pada Pertumbuhan Dan Hasil Bawang Merah (Allium ascalonicum L.) Varietas Manjung. Jurnal Produksi Tanaman. Vol.6 No.1:76-82.

Susilowati, J K, dan Suratiningsih, Sri. 2011. Analisis Perbandingan Pendapatan Usahatani Padi Pengguna Pupuk Anorganik Dan Yang Ditambah Pupuk Organik Di Desa Regaloh Kecamatan Tlogowungu Kabupaten Pati. Jurnal Agmomedia. Vol. 29, No.2: $32-53$

Tabloidsinartani.com, 2018. Mari Tiru MTS Dari Lamongan, Diakses pada tanggal 12 Februari 2019 melalui https://tabloidsinartani.com/detail/i 
ndeks/pangan/7083-Mari-Tiru-

MTS-dari-Lamongan

Taufik, Muhammad. 2010. Pertumbuhan dan Produksi Tanaman Cabai yang Diaplikasi Plant Growth Promoting Rhizobabacteria. J. Agrivigor. Vol.10, No.1: 99-107. 